\title{
Predictors of completed suicide in a cohort of 50465 young men: role of personality and deviant behaviour
}

\author{
Peter Allebeck, Christer Allgulander, Lloyd D Fisher
}

\begin{abstract}
Suicide seems to be increasing in young people in various countries and causes the greatest loss of years of life under the age of 65 in the Swedish population. Data from a national survey of 50465 conscripts in Sweden were used in a prospective follow up study to assess personality and behavioural predictors of suicide in young men. Altogether 247 completed suicides occurred in the cohort during 13 years' follow up. Baseline data on social conditions, psychological assessments, and psychiatric diagnoses of the conscripts were entered into a Cox regression model with suicide as the outcome variable. Several early indicators of antisocial personality (poor emotional control, contact with a child welfare authority or the police, and lack of friends) were strongly predictive of suicide. None of the few conscripts who had a diagnosis of schizophrenia or affective psychosis committed suicide. A diagnosis of neurosis was associated with a twofold increase in the suicide rate and personality disorder with a threefold increase.

Although the risk of suicide is difficult to assess in an unselected population owing to the low base rate of suicide, the predictors identified in the study may help to identify those at high risk in units where people with deviant behaviour and personality disorders cluster.
\end{abstract}

\section{Introduction}

In terms of potential years of life lost from the ages of 1 to 65 suicides account for most lost years in the Swedish population. ${ }^{1}$ Although suicide rates are still highest in people of middle age and older, cohort studies in different countries have consistently shown an increased rate in younger age groups..$^{2-5}$ These findings prompted us to investigate the factors underlying suicide, particularly in young adults, and we performed a retrospective study to determine social and personality predictors of suicide among young Swedish men. The study was made possible by access to personal data collected for all Swedish men who were conscripted during 1969-70.

\section{Subjects and methods} CONSCRIPTION SURVEY

During 1969-70, 50465 men aged 18-20 were con-

Karolinska Institute, Huddinge University Hospital, 14186 Huddinge, Sweden

Peter Allebeck, MD, senior lecturer in social medicine Christer Allgulander, $\mathrm{MD}$, senior lecturer in psychiatry

\section{Department of}

Biostatistics, University of Seattle, Washington,

United States

Lloyd D Fisher, PHD,

professor of biostatistics

Correspondence to: Peter Allebeck, Department of Medicine, Huddinge University Hospital, S-141 86 Huddinge,

Sweden. logists, whose ratings were regularly checked for interrater reliability to maintain the quality of the selection procedure. Details of the procedure as well as results of studies of its validity comparing the assessments with other sources, have been reported by Otto." Whenever a psychiatric disorder was reported by the conscript or suspected he was referred to a psychiatrist, and any diagnosis was coded according to the Swedish version of the International Classification of Diseases (eighth revision).

This procedure was done primarily to place men within the military training scheme; the data collected in 1969-70 were kept for research and were made available by permission of the research ethics committee of the Karolinska Institute and the Swedish Data Inspection Board.

\section{FOLLOW UP}

We used the national register of deaths by cause to identify deaths in the cohort up to and including 1983. The data obtained during conscription were retrieved for all conscripted men who died during this period. The causes of death for all people domiciled in Sweden are coded and recorded at Statistics Sweden from information on their death certificates. Only those men who had emigrated were lost to follow up, which was a negligible number in our age group. The rate of necropsy in our cohort was $84 \%$; altogether $83 \%$ of necropsies were forensic necropsies.

\section{SELECTION OF VARIABLES AND STATISTICAL ANALYSIS}

From the responses to the questionnaire we selected variables that reflected home conditions, behaviour, and use of alcohol and narcotics (see table I). From the psychological assessments we chose to study intellectual ability, mental function, and emotional control. Mental function is a summary assessment of attachment, social maturity, endurance, decision making, and leadership ability. Similarly, emotional control shows stability, emotional maturity, and tolerance to stress and frustration. Crude suicide rates were computed for different levels of exposure to these variables and for the different psychiatric diagnoses at the time of conscription.

Statistical analysis was designed to elucidate the impact of personality and deviant behaviour on the risk of suicide. The outcome death from suicide included the categories suicide (E950-959) and undetermined (E980-989) as in the International Classification of Diseases to minimise the effects of differences in the classification. $^{7 \times}$

We assessed the association between suicide and the set of baseline characteristics described above, including the psychiatric diagnoses, with the Cox proportional hazards regression model. ${ }^{910}$ Time to death from suicide was the dependent variable. We tested the association between suicide and each of 12 variables selected from those described above (univariate analysis) and then entered the variables in a stepwise forward analysis (multivariate model), thus obtaining estimates of relative risk and confidence intervals, controlling for other variables in the model.

\section{Results}

Among 683 deaths from all causes 247 completed suicides (195 definite suicides, 52 undetermined deaths) occurred in the cohort during the follow up, 
TABLE I-Number of suicides 1000 conscripts by category of social conditions. (For each vari able, except when stated otherwise, $p<0.001^{\star}$ )

\begin{tabular}{|c|c|}
\hline Variable & $\begin{array}{l}\text { Suicide } \\
\text { rate }\end{array}$ \\
\hline \multicolumn{2}{|l|}{ Home conditions } \\
\hline \multicolumn{2}{|l|}{ Subject grown up with: } \\
\hline Both parents & $4 \cdot 3$ \\
\hline Mother & $9 \cdot 0$ \\
\hline Father & $10 \cdot 3$ \\
\hline Other caretaker & $14 \cdot 9$ \\
\hline \multicolumn{2}{|l|}{ Father used alcoholt: } \\
\hline Never & $4 \cdot 4$ \\
\hline Rarely & $3 \cdot 6$ \\
\hline Sometimes & $6 \cdot 1$ \\
\hline Often & $11 \cdot 7$ \\
\hline \multicolumn{2}{|l|}{ Behaviour } \\
\hline \multicolumn{2}{|l|}{ Misconduct in school: } \\
\hline Never & $3 \cdot 8$ \\
\hline Once & $6 \cdot 2$ \\
\hline Several times & $13 \cdot 7$ \\
\hline \multicolumn{2}{|c|}{ Subject ran away from home: } \\
\hline Never & $4 \cdot 5$ \\
\hline Once & 8.9 \\
\hline Several times & $23 \cdot 5$ \\
\hline \multicolumn{2}{|c|}{$\begin{array}{l}\text { Contact with police or child welfare } \\
\text { authority: }\end{array}$} \\
\hline None & 3.4 \\
\hline Once & 6.9 \\
\hline Several times & $18 \cdot 3$ \\
\hline \multicolumn{2}{|l|}{ Charged with drunkenness: } \\
\hline Never & $4 \cdot 0$ \\
\hline Once & $9 \cdot 0$ \\
\hline Several times & $28 \cdot 1$ \\
\hline \multicolumn{2}{|l|}{ No of friends: } \\
\hline Three or more & $4 \cdot 5$ \\
\hline Two & $8 \cdot 6$ \\
\hline One & $9 \cdot 4$ \\
\hline None & $19 \cdot 2$ \\
\hline \multicolumn{2}{|c|}{ Use of alcohol and narcotics } \\
\hline \multicolumn{2}{|c|}{ Present intake of spirits: } \\
\hline Never or rarely & $4 \cdot 3$ \\
\hline Once or twice a month & $4 \cdot 5$ \\
\hline Once a week & $7 \cdot 5$ \\
\hline Several times a week & $23 \cdot 8$ \\
\hline \multicolumn{2}{|c|}{ Present intake of wine and beer $\neq$ : } \\
\hline Never or rarely & $4 \cdot 5$ \\
\hline Once or twice a month & $4 \cdot 4$ \\
\hline Once a week & $4 \cdot 8$ \\
\hline Several times a week & $6 \cdot 7$ \\
\hline \multicolumn{2}{|l|}{ Use of narcotics: } \\
\hline Never & $4 \cdot 2$ \\
\hline Ever & \\
\hline \multicolumn{2}{|l|}{ No of times narcotics use } \\
\hline $1-4$ & \\
\hline $5-10$ & 6.6 \\
\hline $11-50$ & $4 \cdot 3$ \\
\hline$>50$ & $23 \cdot 3$ \\
\hline \multicolumn{2}{|c|}{ Use of intravenous narcotics\|: } \\
\hline Never & $6 \cdot 1$ \\
\hline Once & $14 \cdot 9$ \\
\hline Several times & $29 \cdot 9$ \\
\hline
\end{tabular}

Based on $\chi^{2}$ test for trend (ordinary $\gamma^{2}$ test used for parental care variable

$\mathrm{tp}=0.007 . \neq \mathrm{f}=0 \cdot 026 . \quad \mathrm{p}=0 \cdot 175$ tp $=0.007$

$\mathrm{p}=0.019$ giving a rate of 4.9 suicides per 1000 conscripts. Table I shows the suicide rates by category of response to questions about social risk factors. Most of the variables we had selected were strongly related to the suicide rate. Some, however, were not significant, possibly owing to the few subjects with high levels of exposure to each variable. When the suicide rate was analysed in terms of the psychological assessments it was significantly higher in men with low intellectual capacity $(\mathrm{p}<0.001)$, low emotional control $(\mathrm{p}<0.001)$, and low social maturity $(\mathrm{p}<0.001)$.

Table II shows the suicide rates among conscripts who had been assessed by a psychiatrist. Few conscripts had a diagnosis of schizophrenia or affective disorder, and none of them committed suicide. Neurotic and personality disorders were significantly associated with high suicide rates. The suicude rate was highest among men with personality disorders.

TABLE II-Suicides among conscripts with psychiatric illness

\begin{tabular}{|c|c|c|c|}
\hline Diagnosis & $\begin{array}{c}\text { No of } \\
\text { conscripts }\end{array}$ & $\begin{array}{c}\text { No of } \\
\text { suicides } 1000\end{array}$ & p Value* \\
\hline Schizophrenic psychosis (ICD 295) & 15 & 0 & NS \\
\hline Affective disorder (ICD 296 & 14 & 0 & NS \\
\hline Neurotic disorder (ICD 300) & 2584 & $10 \cdot 9$ & $<0.001$ \\
\hline Personality disorder (ICD 301 ) & 1366 & $15 \cdot 6$ & $<0.001$ \\
\hline
\end{tabular}

ICD $=$ International Classification of Diseases

* Based on $\gamma^{2}$ test of difference in suicide rate from that for rest of cohort or on test based on Poisson distribution (for small numbers of conscripts .

Table III shows the association of the baseline characteristics with suicide in the Cox model. Poor emotional control was the variable most predictive of suicide; contact with police or a child welfare authority, lack of friends, and misconduct in school were also highly predictive. Social immaturity and a diagnosis of psychiatric disease, which were associated with suicide in the univariate analysis, were excluded in the multivariate model as their predictive power overlapped with other variables in the model.

\section{Discussion}

We believe that our study is unique in that it comprises data from questionnaires and interviews on a large cohort of young men in the general population and virtually complete data on mortality during 13 years' follow up. The data were, however, collected for military purposes, not for the purposes of this study, and were not validated against other sources or during follow up. The quality of the data recorded at conscription is thus of concern. Otto assessed military suitability, diagnoses when conscripts were listed as being ill, and men exempted in relation to baseline data collected at conscription and concluded that diagnoses of psychiatric disease, intellectual capacity, mental function, and emotional stability determined performance during military service. ${ }^{6}$ Thus the psychological

TABLE III-Association between baseline characteristics and suicide by univariate Cox analysis and step u multivariate analysis. Relative risk computed for each unit increase in level of exposure compared with previous level

\begin{tabular}{lccc}
\hline Baseline characteristic (No of levels of exposure) & $\begin{array}{c}\text { Univariate } \\
\mathrm{p} \text { value }\end{array}$ & $\begin{array}{c}\mathrm{p} \text { Value in } \\
\text { final model }\end{array}$ & $\begin{array}{c}\text { Instantaneous relative } \\
\text { risk }(95 \% \\
\text { confidence interval) }\end{array}$ \\
\hline Poor emotional control (1-5) & $<0.001$ & $<0.001$ & $1.41(1.22$ to 1.64$)$ \\
Contact with police or child welfare authority (1-3) & $<0.001$ & $<0.001$ & $1.45(1.17$ to 1.81$)$ \\
No of personal friends (1-4) & $<0.001$ & $<0.001$ & $1.32(1.15$ to 1.51$)$ \\
Misconduct in school (1-3) & $<0.001$ & 0.001 & $1.41(1.14$ to 1.71$)$ \\
Father heavy drinker (1-4) & $<0.001$ & 0.023 & $1 \cdot 20(1.03$ to 1.41$)$ \\
Broken home (1-4) & $<0.001$ & 0.036 & $1.24(1.02$ to 1.50$)$ \\
Low intellectual capacity & $<0.001$ & 0.058 & $1.06(1.00$ to $1 \cdot 14)$ \\
Social immaturity & $<0.001$ & 0.570 & \\
Run away from home & $<0.001$ & 0.470 & \\
Heavy drinker & $<0.001$ & 0.774 & \\
Narcotics abuse & 0.143 & 0.579 & \\
Psychiatric illness & $<0.001$ & 0.399 & \\
\hline
\end{tabular}

tests served the purpose of selection for military service. Benson and Holmberg validated externally the conscripts' responses to questions about use of alcohol and narcotics and found that most items had been correctly classified in $80-90 \%$ of cases. ${ }^{.1}$ Data collected at conscription that were used by Angst and Clayton 13 were validated in a separate report and were consistent with data collected by other methods. ${ }^{13}$ The data collected at conscription thus seem to be valid for the purposes of our study. Misclassification of the level of exposure to each variable would in general tend to reduce the risk ratio of the outcome in question; more accurate measurements would only strengthen the findings.

Few studies have assessed risk factors for completed suicide among young people. Angst and Clayton followed up a group of conscripts and, on the basis of 15 completed suicides, concluded that depression combined with high scores for aggression increased the risk. ${ }^{12}$ In the San Diego suicide study substance abuse was a risk factor among people under 30 , especially those in the later stages of their addiction. ${ }^{14}$ Shafii et al retrospectively investigated personality characteristics among people who completed suicide at 12-19 years of age and found a high proportion of antisocial behaviour and personality disturbances in this group compared with a control group. ${ }^{14}$ Otto prospectively followed up children and adolescents who had attempted suicide and reported that disorders of adjustment and emotional instability were conducive to completed suicide. ${ }^{16}$

The results of these studies agree with our findings that poor emotional control and early deviant behaviour predict suicide. Besides as a component of inhibited personality in one study, "we have not found any other report of the predictive value of a lack of friends in completed suicide. This characteristic was as predictive as misconduct in school and social immaturity, which shows that a restricted social network may be important. Diagnosis of psychiatric disease was not predictive in the multivariate model, although a personality disorder was related to suicide in the univariate analysis. Paffenbarger and Asnes found that emotional instability and lack of sociability were risk factors for suicide in a study of the case records of 40000 former college students in America; early loss or absence of their father was also predictive for men but not women. ${ }^{17}$ In our study men who had grown up with only one parent had an increased suicide rate, but the rate was virtually the same whether the parent was the father or the mother (table I). This may reflect historical differences in family life: most of the cases studied by Paffenbarger and Asnes were from the period 1930-40, and practices of bringing up children and divorce rates have changed subsequently in Sweden and America.

Recently Hendin and Hawton reviewed suicide risks. ${ }^{19}$ Psychiatric illness (depression, schizophrenia, and alcoholism), genetic factors, biochemical markers, and sociodemographic characteristics have consistently been reported to be associated with suicide. Most studies, however, have been of patients with psychiatric illness or have focused on sociodemographic factors of a general nature, such as being male and widowed. ${ }^{18}$ Hendin emphasised the need to elucidate psychological and social characteristics further and to integrate them with psychobiological markers. For example, a low concentration of 5hydroxyindoleacetic acid in cerebrospinal fluid, which is a biochemical marker for suicide, has been associated with hostile and aggressive behaviour, expressed anger, fearlessness, and social dominance. ${ }^{201}$ Our findings on early deviant behaviour and a lack of friends point to the need for further research into antisocial personality traits conducive to suicide. 
Although the suicide rate was high among men who had reported using narcotics more than 50 times, this variable was not a significant predictor in the Cox analysis, probably because few conscripts reported such heavy use. Yet the highest suicide rate (30/1000) was found among men who reported intravenous drug use. Similarly, alcohol use was associated with a high risk of suicide only among heavy drinkers-that is, those who drank spirits several times a week (table I).

In several recent articles the possibility of predicting suicide in patients with psychiatric illness has been discussed. ${ }^{22-24}$ Pokorny concluded from a prospective study of 4800 such patients that the low sensitivity and specificity of risk factors and the low base rate of suicide made it impossible to predict suicide in individual cases. ${ }^{22}$ Motto et al took a more optimistic view and developed a clinical instrument to estimate the risk of suicide based on a follow up of 2753 patients with psychiatric disease, although they pointed out its limitations. ${ }^{23}$ Prediction of suicide in individual cases is even less feasible in an unselected population of conscripts as the base rate of suicide is much lower than that among patients with psychiatric illness. ${ }^{2+25}$ Thus our findings cannot be used to create an instrument to screen men at conscription.

Preventing suicide in individual cases is most effective in settings in which the associated risk factors are frequent. Thus people at risk tend to be seen by the social services, in treatment programmes for substance abuse, and in delinquency units. Knowledge of the predictors of suicide within these units may facilitate identification of those at risk and intervention. Future research should focus on markers of antisocial traits conducive to suicide in young men.

The study was supported by a grant from the Swedish Medical Research Council, No B88-27X-08322-01. We acknowledge the help of Per Näsman with the computer programming.
1 Wall S, Rosén M, Nyström L. The Swedish mortality pattern: a basis for health planning. In 7 Epidemiol 1985;14:285-92.

2 Murphy GR, Wetzel RD. Suicide risk by birth cohort in the United States 1949 to 1974. Arch Gen Psychiatry 1980;37:519-23.

3 Solomon MI, Hellon CP. Suicide and age in Alberta, Canada, 1951 to 1977. Arch Gen Psychiaty 1980;37:511-3.

4 Goldney RD, Katsikis M. Cohort analysis of suicide rates in Australia. Arch Gen Psychiatry 1983;40:71-4.

5 Nordström P, Åsgărd U. Suicide risk by age and birth cohort in Sweden. Crisis 1986;7:75-80.

6 Otto U. Function of male youths during military service. Acta Psychiatr Scand [Suppl] 1980;282:1-59.

7 Barraclough BM. Differences between national suicide rates. $\mathrm{Br} f$ Psychiatry 1973;122:95-6

8 Bolander A-M, Ettlinger R. Suicide in Sweden. In: Health and societv. V. Different aspects of mortality in Sweden. Stockholm: Committee for Future Different aspects of mortality in Sweden. Stockholm: Comm

9 Cox DR. Regression models and life tables. Fournal of the Royal Statistical Society 1972;343:187-200.

10 Allgulander C, Fisher LD. Survival analysis (or time to an event analysis) and the Cox regression model-methods for longitudinal psychiatric research. Acta Psychiatr Scand 1986;74:529-35.

11 Benson G, Holmberg MB. Validity of questionnaires in population studies on drug use. Acta Psychiatr Scand 1985;71:9-18.

12 Angst J, Clayton P. Premorbid personality of depressive, bipolar, and schizophrenic patients with special reference to suicidal issues. Comp Psychiatry 1986;27:511-32.

13 Ruppen R, Müller U, Baumann U, Angst J. Zur Prüfung der Aussagegenauigkeit bei einer Befragung über Drogenkonsum. Zeitschrift für Präventivmedizin 1973:18:173-81.

14 Rich CL, Young D, Fowler RC. San Diego suicide study. I. Young vs old subjects. Arch Gen Psychiatry 1986;43:577-82.

15 Shafii M, Carrigan S, Whittinghill JR, Derrick A. Psychological autopsy of completed suicide in children and adolescents. Am F Psychiatry 1985;142: $1061-4$

16 Otto U. Suicidal acts by children and adolescents. Acta Psychiatr Scand [Suppl] 1972;233:1-123.

17 Paffenbarger RS, Asnes AP. Chronic disease in former college students. III. Precursors of suicide in early and middle life. Am $\mathcal{J}$ Public Healt 1966;56:1026-36

18 Hendin H. Suicide: a review of new directions in research. Hosp Community Psychiatry 1986;37:148-54.

19 Hawton K. Assessment of suicide risk. Br f Psychiatry 1987; 150:145-53.

20 Brown GL, Goodwin FK. Human aggression and suicide. Suicide Life-Threat Behav 1986;1:223-39.

21 Åsberg M. Biochemical aspects of suicide. Clin Neuropharmacol 1986;9(suppl 4):374-6.

22 Pokorny AD. Prediction of suicide in psychiatric patients. Arch Gen Psychiatry 1983;40:249-57.

23 Motto JA, Heilbron DL, Juster RP. Development of a clinical instrument to estimate suicide risk. Am $\mathcal{F}$ Psychiatry 1985;142:680-6.

24 Murphy GE. On suicide prediction and prevention. Arch Gen Psychiatry 1983;40:343-4.

25 Galen RS, Gambino SR. Beyond normality: the predictive value and efficiency of medical diagnoses. New York: John Wiley and Sons, 1975.

(Accepted 12 April 1988)
Department of

Microbiology,

Wythenshawe Hospital,

Manchester M23 9LT

Barbara J Isalska, MB, senior registrar

T N Stanbridge, FRCPATH, consultant microbiologist

Correspondence to: Dr Isalska.

\section{Fluconazole in the treatment of candidal prosthetic valve endocarditis}

\author{
Barbara J Isalska, T N Stanbridge
}

We report the first use of fluconazole in the treatment of prosthetic valve endocarditis due to Candida parapsilosis.

\section{Case report}

A 37 year old woman presented with a six week history of anorexia with nausea, weight loss, fever, sweats, and rigors. Sixteen weeks earlier, because of failure of a xenograft inserted eight years previously, she had undergone mitral valve re-replacement with a Starr-Edwards valve. Culture of the excised valve yielded a growth of Staphylococcus albus, which was considered to be a contaminant, from fluid medium only. Convalescence was complicated by a serous discharge from the wound in the groin through which cardiac bypass had been established. The exudate was not cultured.

On examination she was feverish $\left(38.5^{\circ} \mathrm{C}\right)$ and sweating but not in cardiac failure. There were no other features of endocarditis. Haemoglobin concentration was $114 \mathrm{~g} / \mathrm{l}$, white cell count $6 \cdot 7 \times 10^{9} / 1$, and erythrocyte sedimentation rate $35 \mathrm{~mm}$ in the first hour. Serum creatinine and liver function values were normal and repeated echocardiograms were noncontributory. Five separate blood cultures yielded $C$ parapsilosis. Further surgery was judged to be unacceptably hazardous and she was treated with a total of $2.05 \mathrm{~g}$ amphotericin B. Six blood cultures over the next two months grew no pathogens.

Six months later the patient was readmitted with a four day history of myalgia, headache, and fever and had developed a mitral regurgitant murmur. $C$ parapsilosis was isolated from five of six blood cultures. Treatment with flucytosine and amphotericin B was begun but replacement of the infected valve was again considered to be unacceptably hazardous. Investigations failed to identify any other focus of fungal infection, and because of deteriorating renal function alternative antifungal treatment was sought.

Oral treatment with $200 \mathrm{mg}$ fluconazole daily was instituted and the prothrombin time closely monitored because of concomitant treatment with nicoumalone. Five days later, however, she suffered an intracranial haemorrhage (prothrombin time $170 \mathrm{~s}$; control $15 \mathrm{~s}$ ). A computed tomogram showed a $4 \mathrm{~cm}$ space occupying lesion with a density of blood in the upper left parietal region, and histological examination and culture of the surgically evacuated clot failed to detect the presence of fungi. Owing to deteriorating renal function the fluconazole was reduced to $100 \mathrm{mg} / \mathrm{day}$ and she continued with this dose, though her renal function subsequently improved (figure). Twelve sets of blood 